\title{
GENERALIZED LINEAR MODELS APPLIED TO STRANDING DATA OF SOUTH AMERICAN SEA LIONS (OTARIA FLAVESCENS) AND SOUTH AMERICAN FUR SEALS (ARCTOCEPHALUS AUSTRALIS) IN SOUTHERN BRAZIL ${ }^{1}$
}

\author{
Paul G. Kinas ${ }^{2, *}$, Kleber G. da Silva ${ }^{3}$, Sérgio C. Estima ${ }^{3}$ and Danielle da S. Monteiro ${ }^{3}$
}

\begin{abstract}
Aвstract: Monthly strandings of South American sea lions, Otaria flavescens, and South American fur seals, Arctocephalus australis, collected between 1993 and 2002 along the coastline of Rio Grande do Sul, Brazil, are analysed with generalized linear models (GLM) to describe spatial and temporal stranding patterns and to estimate the annual number of stranded animals by species. Results indicate a strong seasonal pattern for both species with maximum average number of strandings in September and minimum in January. While year effects are not significant, differences between regions (north or south of the Patos Lagoon mouth) are. Estimated numbers of stranded sea lions and fur seals in a typical year are 115, with 95\% confidence interval (76; $160)$ and 95 , with $95 \%$ confidence interval $(48 ; 180)$, respectively. GLMs proved to be a very useful tool to examine the influence of time and space on strandings in a statistically rigorous framework.

REsumo: Encalhes mensais de leões marinhos do sul, Otaria flavescens, e lobos marinhos do sul, Arctocephalus australis, registrados do ano de 1993 até 2002 ao longo da costa do Rio Grande do Sul, Brasil, são analisados com modelos lineares generalizados (GLM) a fim de descrever padrões espaciais e temporais bem como estimar o número anual de encalhes efetivos por espécie. Os resultados indicam um forte padrão sazonal para ambas as espécies com máximo de encalhes em setembro e mínimo em janeiro. Enquanto efeitos anuais não são significantes, diferenças regionais (ao norte e ao sul dos molhes da Lagoa dos Patos) o são. Os números anuais de encalhes estimados para leões e lobos marinhos são 115 e 95, respectivamente, com intervalo de confiança de $95 \%$ (76; 160) e $(48 ; 180)$. GLMs se mostraram ferramentas úteis para examinar de forma estatisticamente rigorosa, as influências de tempo e espaço nos encalhes de pinípedes.
\end{abstract}

KEYwORDs: generalized linear models, pinniped, strandings, South American sea lion, South American fur seal, Otaria flavescens, Arctocephalus australis, southern Brazil.

\section{Introduction}

Ordinary linear regression has played a central role in classical applied statistics due to the possibility to model empirically some stochastic response variable $(Y)$ as a linear function of a set of explanatory variables $\left(x_{1}, x_{2}, \ldots, x_{k}\right)$. However, as the range of applications grew with time, restrictions imposed by the requirements of a Gaussian probability distribution for $Y$ and constant variance over the range of observed values of $\left(x_{1}, x_{2}, \ldots, x_{k}\right)$ became apparent. Generalized linear models (GLMs; McCullagh and Nelder, 1989; Dobson, 2002) attempt to accommodate both restrictions simultaneously by extending linear regression in an effective way.

The components of a GLM are as follows:

(i) the response variable $Y$ follows a probability distribution of known form within the exponential family of distributions. This family includes continuous distributions like the Gaussian and gamma, as well as discrete distributions like Poisson, binomial and negative binomial;

(ii) the distribution of $Y$ depends on a set of explanatory variables through a single linear predictor, $\eta=\sum^{k} x_{j} \beta_{j}$, where $x_{j}$ are known functions of a selection of $k$ explanatory variables and $\beta_{j}$ unknown parameters to be estimated from the data; (iii) the linear predictor $\eta$ is related to the mean of $Y, \mathrm{E}(Y)=\mu$ by a known link function g; namely $\eta=g(\mu)$;

(iv) the variance of $Y$ is a function of $\mu$ and a scale parameter $\phi$. For the Poisson distribution $\phi=1$, while for the negative binomial or the Gaussian distributions, $\phi$ is usually unknown and has to be estimated from the data.

In light of the above definitions, it is clear that linear regression is just a special case of GLMs that results when the distribution of $Y$ is Gaussian and the link function is identity $\eta=\mu$. In contrast, stranding data are counts $(0,1,2,3, \ldots)$ for which discrete probability distributions such as the Poisson or negative binomial are better candidates. The link function in both cases is the natural logarithm, namely $\eta=\log (\mu)$.

For an excellent overview of GLMs and other related modeling processes the reader is referred to Venables and Dichmont (2004). Additional theoretical considerations can be found in Dobson (2002) and Ripley (2002).

An up-to-date review of published accounts on pinniped occurrences along the Brazilian coastline over the last 30 years is given in Silva (2004). Despite its historical value, this collection of isolated events neither allows for comparative studies in time or space, nor quantifies the number of strandings in a statistically rigorous way. There are studies about the dynamics of movements

\footnotetext{
${ }^{1}$ The term "stranding" is generally used when the animal(s) is (are) still alive when reaching the beach, however, here the term will also refer to dead animals that were washed ashore.

${ }^{2}$ Fundação Universidade Federal do Rio Grande (FURG), Dep. Matemática, Laboratório de Estatística. Av. Itália, km 8, $96201-900$ Rio Grande RS Brazil. E-mail: dmtkinas@furg.br.

${ }^{3}$ Núcleo de Educação e Monitoramento Ambiental (NEMA).

"Corresponding author, e-mail: dmtkinas@furg.br
} 
along the Rio Grande do Sul coast, and occupancy patterns of wintering concentrations at the Patos Lagoon's east jetty (Molhe Leste) and the Lobos island (Ilha dos Lobos) for sea lions Otaria flavescens by Rosas (1989), Rosas et al.(1994) and in several unpublished technical reports. Due to its coastal distribution and feeding behavior, O. flavescens suffers aggression from fishers and aquaculture workers throughout its range (Silva, 2004). Along the Rio Grande do Sul coast the interaction with fisheries is pointed out as the main cause mortality in this species (Rosas, 1989; Pinedo, 1990; Silva, 2004).

This article illustrates the use of GLMs to describe the observed stranding of South American fur seals (Arctocephalus australis) and South American sea lions (Otaria flavescens) along the coastline of Rio Grande do Sul, southern Brazil, according to location, time and search effort (i.e. percentage coastline coverage). The analysis is aimed at (i) describing the spatial and temporal patterns in strandings and (ii) estimating the absolute number of annual stranding for both species.

\section{Methods}

\section{Study Area and Data Collection}

The Rio Grande do Sul coast is a $623 \mathrm{~km}$ long sandy shoreline between Torres $\left(29^{\circ} 21^{\prime} S\right)$ and Chui $\left(33^{\circ} 45^{\prime} \mathrm{S}\right)$, south Brazil (Figure 1). The region is under direct influence of the subtropical convergence of the western South Atlantic Ocean and is considered one of the most productive fishery grounds in Brazil (Seeliger et al.,1997).

Between January 1993 and December 2002 a total of 182 expeditions were conducted along the coast. Of these, 98 expeditions covered the region to the south of the Patos Lagoon jetties and 84 covered the northern region with an average search effort of $2746.2 \mathrm{~km} /$ year ( $\mathrm{sd}=496 \mathrm{~km}$ ). The percentage coverage per month is described in Table 1.

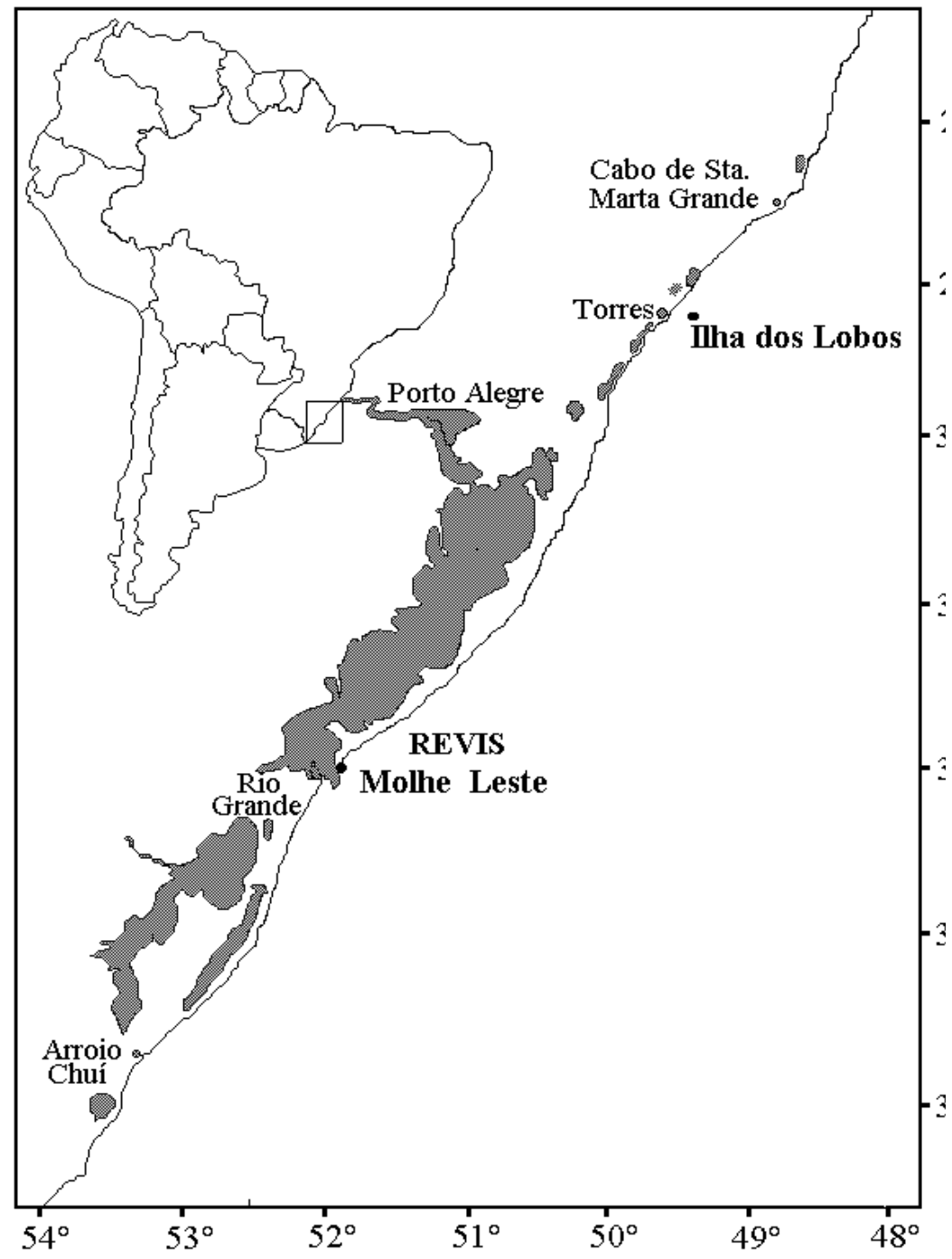

Figure 1. The study area: the coastline of Rio Grande do Sul, Brazil, between Torres and Arroio Chuí highlighting the Molhe Leste wildlife reserve (REVIS = Reserva da Vida Silvestre). 
Table 1. Percentage coverage of coastline by month and year (1993-2002).

\begin{tabular}{|c|c|c|c|c|c|c|c|c|c|c|}
\hline \multirow{2}{*}{ MONTH } & \multicolumn{10}{|c|}{ YEAR } \\
\hline & 1993 & 1994 & 1995 & 1996 & 1997 & 1998 & 1999 & 2000 & 2001 & 2002 \\
\hline Jan & 35.3 & 27.1 & 20.9 & 61.6 & 3.9 & 54.9 & * & 18.0 & * & 57.3 \\
\hline Feb & 60.2 & 21.7 & 10.6 & 35.3 & 62.1 & 22.6 & * & 17.8 & * & 57.0 \\
\hline Mar & * & 35.3 & 25.4 & 74.3 & 35.3 & 100.0 & 22.0 & 17.0 & * & 76.7 \\
\hline Apr & 12.8 & 10.6 & 11.6 & 36.1 & 35.3 & 36.3 & 8.0 & 17.7 & 100.0 & * \\
\hline May & 25.8 & 10.6 & 61.8 & 58.1 & 39.3 & 43.3 & 37.1 & 19.3 & 100.0 & 57.5 \\
\hline Jun & 22.0 & * & 68.7 & 57.8 & 35.3 & 22.2 & 1.9 & 17.3 & 100.0 & 17.7 \\
\hline Jul & 34.3 & 35.3 & 43.2 & 1.9 & 47.8 & 80.4 & 28.6 & 19.1 & 100.0 & 57.0 \\
\hline Aug & 20.7 & 9.6 & 40.6 & 71.7 & 41.7 & 50.9 & 17.2 & 1.9 & 45.6 & 1.9 \\
\hline Sep & 1.9 & 36.9 & 90.4 & 50.7 & 60.7 & 61.2 & 31.8 & 1.9 & 42.4 & 68.1 \\
\hline Oct & 35.3 & * & 67.3 & 36.1 & 71.4 & 23.6 & 23.0 & 5.3 & 100.0 & * \\
\hline Nov & 5.3 & 57.9 & 60.5 & 64.2 & 49.0 & 48.3 & 20.5 & 1.9 & 100.0 & 93.7 \\
\hline Dec & 5.3 & 46.9 & 29.1 & 55.5 & 62.0 & 16.1 & 23.0 & 3.9 & 80.9 & 18.5 \\
\hline $\operatorname{Avg}(1)$ & 23.5 & 29.2 & 44.2 & 50.3 & 45.3 & 46.7 & 22.8 & 11.8 & 85.4 & 50.5 \\
\hline
\end{tabular}

$\left(^{*}\right)$ month without expedition; $\left(\operatorname{Avg}^{(1)}\right)$ average monthly coverage.

Expeditions with two or three observers were carried out on a four-wheel drive vehicle travelling at an average speed of about $45 \mathrm{~km} / \mathrm{h}$. Along with the counting of all stranded pinnipeds by species, gender of each specimen was determined based on external characteristics, and biometric measurements were also taken. Location along the coastline and evidence of interaction with fisheries were also registered. Each sampled carcass was marked with spray to avoid double counting in later expeditions. Species identification followed the regional field guide by Pinedo et al. (1992). All dead animals were classified according to their stage of decomposition in a scale from 1 to 5 as follows: (G1) recent death; (G2) rigor mortis and intact carcass; (G3) carcass with strong odor and fluid releases; (G4) putrifying and slightly destroyed carcass; (G5) strongly putrified and destroyed carcass. Detailed descriptions of these data are available in Silva (2004). For the present study, only carcasses that could be identified as $O$. flavescens and $A$. australis were considered.

\section{Statistical Analysis}

We assume as our working hypothesis that the number of observed stranded animals (Y) of a given species is possibly affected by the explanatory variables month, year, location along the coast and sampling effort. By modelling $\mathrm{Y}$ as a function of these explanatory variables, we expect that the effect of each can be quantified and statistically examined. Furthermore, we plan to use the adjusted model to predict strandings for those months in the time series which do not have any observations or that have only partial coverage of the coastline. Because $Y_{s}$ are counts, hence discrete random variables, the use of a GLM seems appropriate. Two candidate probability distributions are examined.

$$
\begin{aligned}
& \mathrm{Y}_{i} \sim \operatorname{Poisson}\left(\mu_{i,} \phi=1\right) \\
& \mathrm{Y}_{i} \sim \operatorname{Negative~binomial~}\left(\mu_{i,} \phi\right)
\end{aligned}
$$

for all data points $i=1, \ldots, n$.

Furthermore, we assume a linear relation between $\eta_{i}=$ $\log \left(\mu_{i}\right)$ and the explanatory variables months (1 to 12$)$, year (1993 to 2002), region (south and north of the Patos Lagoon jetties) and effort (kilometers of coastline covered). It should be noted that variables month, year and region are categorical (with 12, 10 and 2 levels, respectively) while effort is quantitative.

Five alternative models are proposed:

Model 1: $\eta=$ constant + month + region + effort

Model 2: $\eta=$ constant + month + region + region $x$ effort Model 3: $\eta=$ constant + month + region + year + effort Model 4: $\eta=$ constant + month + region + year + region $x$ effort

Model 5: $\eta=$ constant + month + region + region $x$ month + region $x$ effort

Model 1 considers only the effects of month, region and amount of effort on changes in $\eta$. Model 2 is an extension of Model 1, by assuming that both regions have different angular coefficients for effort. Model 3 extends Model 1 by including the year effect while Model 4 is a similar extension of Model 2. Finally, Model 5 extends Model 2 with the inclusion of region-month interactions. It should be noted that the number of model parameters $(\beta)$ grows from Model 1 to Model 5; namely 14, 15, 23, 24 and 26. Model 1 is said to be nested in Model 2 which is nested in both Model 4 and Model 5. Model 1 is also nested in Model 3, whereas Model 2 is not. The advantage of this structured construction of models will become apparent in statistical hypotheses testing described below. 


\section{Model selection}

The combination of two choices of probability distributions for $Y$ with five models for the linear predictor $\eta$ produces ten possible candidate models. Therefore, a procedure to empirically select a best model is necessary. Two information-theoretic criteria are commonly used to assist this choice: Akaike's information criterion (AIC; Burnham and Anderson, 2002) and the Bayesian information criterion (BIC; Schwartz, 1978). To search for a better model is thus equivalent to looking for smaller values of AIC or BIC.

$$
B I C=-2 \log \hat{L}+p \log n
$$

Both criteria use the likelihood function of Ys evaluated at its maximum $(\hat{L})$ and differ in their additional penalty term. While AIC only penalizes the total number of model parameters $(p)$, BIC also includes the number of observations $(n)$. One consequence of this difference is that, as the number of data points increases, it is more difficult to accept more parameters with BIC than with AIC.

Another important criterion to compare nested models using standard statistical hypotheses testing is the deviance. For a given model $\mathrm{M}$ and scale parameter $\phi$, the deviance $\left(\mathrm{D}_{\mathrm{M}}\right.$; Venables and Dichmont, 2004) is calculated in reference to the saturated, most general model S:

$$
D_{M}=2\left(\log \hat{L}_{\mathrm{S}}(\phi)-\log \hat{L}_{M}(\phi)\right)
$$

A more technical description of deviance is not intended here and can be found in the specialized literature on GLMs (e.g. Dobson, 2002, p.77).

\section{Estimating the number of annual strandings}

After selecting some "best model", predicted estimates of the average number of strandings $\hat{\mu}=\exp \left(\hat{\eta}_{i}\right)$ for all months within the study period are calculated by assuming a complete coverage of the study area (this is achieved by setting effort such that the coastline is completely covered: i.e. effort $=220 \mathrm{~km}$ in the southern region and effort $=403 \mathrm{~km}$ in the northern region). This procedure produces estimates of expected strandings which are comparable in time and between regions.

To estimate the absolute number of yearly stranded animals, we sampled $Y_{s}$ from 24 negative binomial distributions, each with some parameter $\hat{\mu}$, denoting a particular combination of month and region $(12 x$ $2=24$ cases), and the scale parameter $\phi$, and where both parameters were estimated based on the final selected model. The summation of these 24 simulated $Y$ s gives an estimate of the total number of yearly stranded animals. The procedure just described was replicated 1000 times in order to assess variability and obtain bootstrap confidence intervals.
All statistical computations were performed using the software $\mathrm{R}$ version 2.0. (R Development Core Team, 2004).

\section{Results}

Model selection

Some preliminary residual analysis of the data indicated an outlier observation of 52 stranded animals that occurred in the southern region during October 1993 for O. flavescens. Similarly, an outlier observation of 47 stranded animals was identified in the southern region in December of 1997 for A. australis. Both were removed from the data set before performing the statistical analysis below.

The values of AIC and BIC for all models are summarized in Table 2. Two features emerge clearly for both species. First, the negative binomial distribution fits consistently better than the Poisson. Second, given a negative binomial distribution for $Y$, the best model based on AIC and BIC are Model 4 and Model 2, respectively. This comes as no surprise since it is known that BIC favors more parsimonious models then does AIC. All analyses that follow refer to model M07 only (i.e. Model 2 with a negative binomial distribution for $Y$ ).

\section{Parameter estimates}

The selected GLM fitted to stranding data of $O$. flavescens and $A$. australis produced the parameter estimates listed in Table 3 (columns 2 and 5). The baseline estimate of the logarithm of the expected number of strandings $\eta=\log \mu$ south of the jetties (region 1 (s)) in January (month 1) is given by the intercept. This value is adjusted differently for the amount of effort in both regions as given by the coefficients (effort (s) and effort (n)). Finally, increments for different months of the year (month 2 to month 12) are also added.

For O. flavescens, the months of May, June and, most importantly, August until November (with peak in September) have statistically significant increments in $\eta$. The effect of each unit of effort induces different increments in each region as indicated by different coefficients. For A. australis the monthly effects are similar with significant increments in $\eta$ between June until November (with peak in September). The coefficient adjusting for amount of effort is only significant in the southern region. For both species the effect for the northern region (region 2 (n)) is statistically unimportant. The last line of Table 3 displays the maximum likelihood estimates of $\phi$ and their standard errors. While the estimate 2.361 for $O$. flavescens is in clear support of a negative binomial over-dispersion, because it is more than two standard errors away from $\phi=1$, the estimate 0.999 for A. australis is not. 
Table 2. Akaike information criterios (AIC) and Bayesian information criterion (BIC) for models fitted to stranding data of $O$. flavescens and A. australis, south Brazil.

\begin{tabular}{lcccc}
\hline \hline MODEL (DISTRIBITUION FOR Y) & \multicolumn{2}{c}{ O. flavescens } & \multicolumn{2}{c}{ A. australis } \\
& AIC & BIC & AIC & BIC \\
\hline \hline M01. Model 1 (Poisson) & 834.24 & 907.10 & 1008.60 & 1081.46 \\
\hline M02. Model 2 (Poisson) & 785.13 & 863.19 & 974.04 & 1052.10 \\
\hline M03. Model 3 (Poisson) & 805.66 & 925.35 & 834.37 & 954.07 \\
\hline M04. Model 4 (Poisson) & 764.71 & 889.60 & 787.71 & 912.61 \\
\hline M05. Model 5 (Poisson) & 777.68 & 912.99 & 906.44 & 1041.74 \\
\hline M06. Model 1 (neg. binom.) & 740.93 & 813.79 & 707.63 & 780.49 \\
\hline M07. Model 2 (neg. binom.) & 720.74 & $\mathbf{7 9 8 . 8 0}$ & 701.26 & 779.32 \\
\hline M08. Model 3 (neg. binom.) & 742.02 & 861.72 & 689.84 & 809.54 \\
\hline M09. Model 4 (neg. binom.) & $\mathbf{7 1 8 . 5 2}$ & 843.42 & $\mathbf{6 7 5 . 5 3}$ & 800.43 \\
\hline M10. Model 5 (neg. binom.) & 730.40 & 865.71 & 694.73 & 830.03 \\
\hline \hline
\end{tabular}

Obs.: Numbers in bold represent the minimum for each column.

Table 3. Estimates, standard errors and p-values of coefficients for selected generalized linear model (Model 2 with negative binomial distribution) fitted to the number of stranded sea lions (O. flavescens) and fur seals (A. australis) in south Brazil.

\begin{tabular}{lcclccc}
\hline \hline & \multicolumn{5}{c}{ O. flavescens } & \multicolumn{3}{c}{ A. australis } \\
\hline PARAMETER & ESTIMATE & STD. ERROR & P-VALUE & EstiMATE & STD. ERROR & P-VALUE \\
\hline \hline intercept & -1.42 & 0.44 & .0015 & -2.36 & 0.79 & .0032 \\
\hline month 2 & -0.65 & 0.57 & .2587 & 1.49 & 0.84 & .768 \\
\hline month 3 & 0.44 & 0.47 & .3429 & -0.02 & 0.99 & .9878 \\
\hline month 4 & 0.82 & 0.47 & .0840 & 1.28 & 0.87 & .1458 \\
\hline month 5 & 0.86 & 0.43 & .0497 & 1.50 & 0.81 & .0649 \\
\hline month 6 & 0.91 & 0.45 & .0466 & 2.30 & 0.80 & .0047 \\
\hline month 7 & 0.76 & 0.43 & .0803 & 3.03 & 0.77 & .0001 \\
\hline month 8 & 1.45 & 0.43 & .0009 & 3.24 & 0.78 & $.52 \mathrm{E}-6$ \\
\hline month 9 & 1.82 & 0.41 & $.18 \mathrm{E}-6$ & 3.83 & 0.77 & $.15 \mathrm{E}-7$ \\
\hline month 10 & 1.55 & 0.44 & .0006 & 3.09 & 0.79 & .0001 \\
\hline month 11 & 1.65 & 0.41 & $.95 \mathrm{E}-6$ & 2.17 & 0.78 & .0062 \\
\hline month 12 & 0.63 & 0.47 & .1796 & 0.45 & 0.96 & .6437 \\
\hline region $(\mathrm{n})$ & 0.51 & 0.33 & .1195 & 0.54 & 0.44 & .2310 \\
\hline effort $(\mathrm{s})$ & 0.010 & 0.0014 & $.52 \mathrm{E}-13$ & 0.0073 & 0.0020 & .0003 \\
\hline effort (n) & 0.002 & 0.0010 & .0304 & 0.0005 & 0.0015 & .7571 \\
\hline$\varnothing$ & 2.361 & 0.546 & - & 0.9993 & 0.1731 & - \\
\hline \hline
\end{tabular}

\section{Residual Analysis}

Residuals are used to examine the fit of the selected model. The graphical display of residuals against observed strandings (Figure 2; a and c) shows that standardized residuals are within an acceptable range ( -3 and 3$)$. Since $Y$ represents discrete counts while the estimates are nonnegative expectations, there is no surprise that for small values of $Y$ residuals are mostly negative. Particularly for $Y=0$, negative residuals are the only possibility.

The quantile-quantile plots (Figure 2; b and d) further indicate that Gaussian distributions of residuals are acceptable, since the scatterplots are nearly linear.

\section{Simulated Annual Number of Strandings}

Standardized estimates of the expected number of strandings $\hat{\mu}$ assuming complete coverage of the shoreline in all months and years $\left(x_{4}=220 \mathrm{~km}\right.$ in the south (region 1) and $x_{4}=403 \mathrm{~km}$ in the north (region 2)) are shown in Figure 3. These estimates are comparable over time and between regions since the same amount of effort is used in all predictions. For both species there is a strong seasonal pattern with peaks in September. For O. flavescens a secondary peak occurs in December.

Monte Carlo simulations of the number of annual strandings use the estimates displayed in Figure 3 as parameters in negative binomial probability distributions together with the scale parameter $\phi$. 
(a)

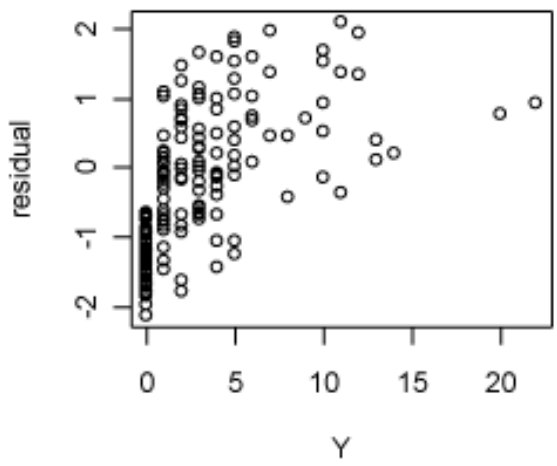

(c)

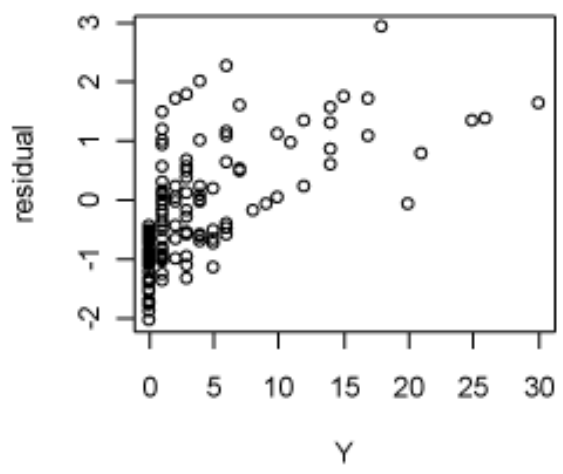

(b)

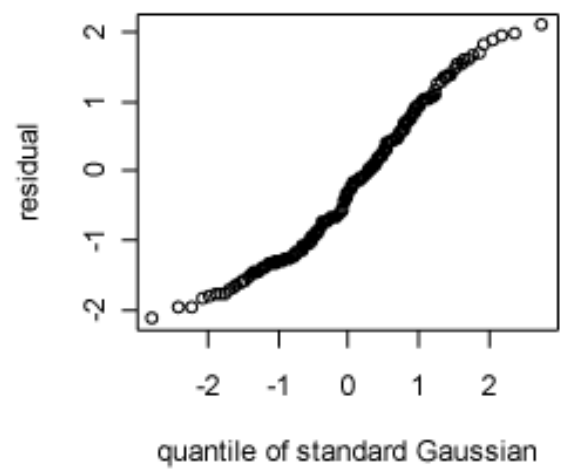

(d)

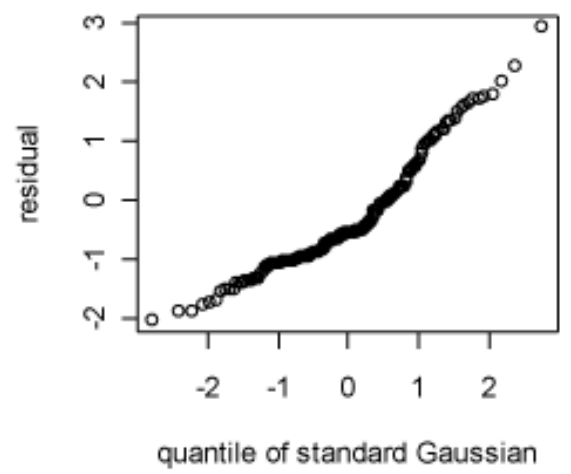

Figure 2. Residual plots for selected Model 2 with negative binomial distribution. O. flavescens (a, b); A. australis (c, d).

Results (Figure 4 and Table 4 ) indicate that the most common number of stranded animals is higher (aprox. 115) for O. flavescens than for A. australis (aprox. 95) but almost twice as variable for the latter $(\mathrm{CV}=32.5 \%)$ when compared to the former $(\mathrm{CV}=18.3 \%)$.

\section{Discussion}

The results show that GLMs are useful to formally analyze the effects of time, space and search effort on the number of stranded sea lions and seals. Since strandings are counts, the possibility to use discrete probability models (Poisson and negative binomial) is very attractive as a means of easily dealing with zeroes, and also of avoiding the need to look for appropriate transformations of the response variable $Y$.

Formal likelihood-ratio tests indicate some significant year effect for both sea lions (LRT $=20.2 ; \mathrm{p}=0.0166)$ and seals $($ LRT $=43.73 ; \mathrm{p}=1.58 \mathrm{e}-06)$. However, year effects present only erratic variations but no trend. In comparison, monthly variations display a stronger and much more important seasonal behavior. Furthermore, the relative increment in AIC is small when going from Model 4 to its simplified alternative Model 2 (1.9\% for $O$. flavescens and $7.7 \%$ for $A$. australis) while BIC clearly favors Model 2. Hence, we believe that the extra complexity derived from Model 4 is not worthwhile and chose Model 2 instead. Nonetheless, in other applications there might be interest in monitoring annual fluctuations in the expected number os strandings - which would require the inclusion of one or more terms in the model to account for them. At first sight it appears that in Model 2 there is no significant region effect with respect to the location being north or south of the Patos Lagoon mouth. However, this effect is included in the distinct angular effort coefficients. Depending on the region the increment per kilometer of covered coastline is statistically different with larger values in the south in comparison to the north. In Model 1, where only one angular coefficient is included, differences between regions become statistically significant and negative in all cases, confirming the pattern of fewer strandings to the north in comparison with the south. The model selection procedure, however, suggests that Model 2 provides a much better overall fit than does Model 1 (smaller AIC and BIC) and was therefore retained instead.

It is instructive to analyze (Figure 3) the discrepancies between the expected number of stranded animals, as provided by the selected models, with the observed averages per month and region. Firstly, the observed averages are mostly smaller than the expected values 
estimated from the model. This is no surprise since the data were collected with unequal amounts of effort, often without covering the entire coastline. Secondly, after eliminating the effect of unequal effort which bias the observed averages, the models identify September as the month in which most strandings occur. Although this result is in line with the data of $A$. australis and with data for the northern region of $O$. flavescens, it does not agree with the data of the latter species for the southern region, which display its peak in November. Thirdly, it can be seen that the differences between observed averages and the standardized expectations provided by the selected models are much larger in the southern region, where the effort coefficients were identified to be quite larger, in comparison to the north.

The simulated numbers of annual strandings (Figure 4) provide a clear idea of the range of possible values for a typical year and can be taken as probability distributions of deaths due to stranding to describe current uncertainties about this phenomenon in population simulation models. Since such models can be important to assist in population management, we believe this to be a very useful result to guide future conservation policies. The relatively small variability observed for $O$. flavescens $(\mathrm{CV}=18.3 \%)$ in comparison to A. australis (CV $=32.5 \%)$ might be a consequence of the coastal routes adopted by sea lions (Vaz-Ferreira, 1981) such that their strandings are less affected by currents and wind directions. We recommend the maintenance of the systematically conducted monitoring program along the Rio Grande do Sul coastline in order to evaluate the evolution of mortality and the impact on population dynamics of these species.
O. flavescens

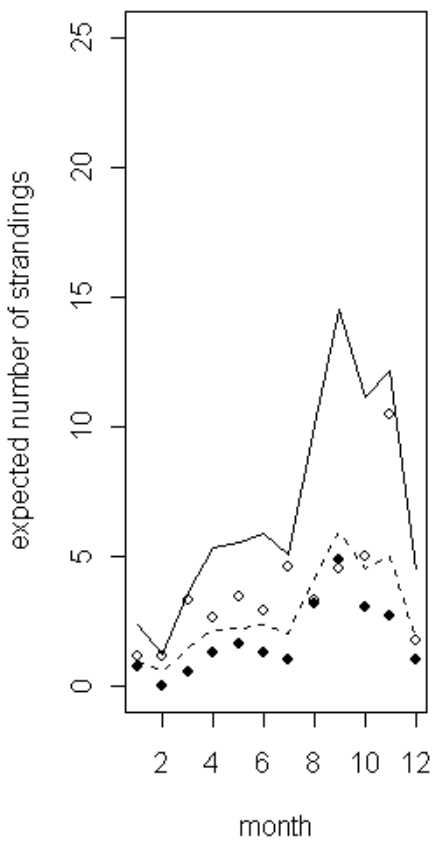

A. australis

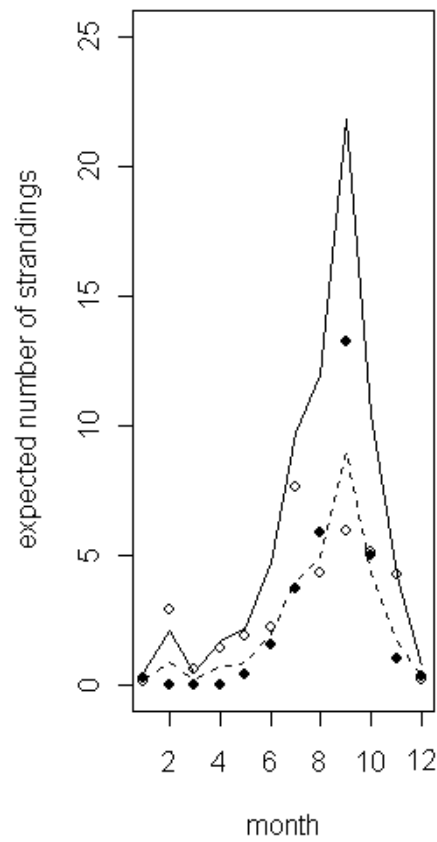

Figure 3. Expected number of strandings $\hat{\mu}$ by month for the southern region 1 ( $\mathbf{C})$ and northern region 2 ( $\boldsymbol{- a}$ ), for sea lions (left) and fur seals (right) in south Brazil. The average number of observed strandings for the southern ( $(\bullet)$ and northern ( $\bullet$ ) regions are also included.

Table 4. Statistical summaries of the simulated total number of strandings for O. flavescens and A. australis south Brazil.

\begin{tabular}{lcc}
\hline \hline SUMMARY STATISTICS & O.flavescens & A. australis \\
\hline \hline Minimum & 48 & 31 \\
\hline Median & 113 & 95 \\
\hline Mean & 114.5 & 99.6 \\
\hline Mode & $\sim 115$ & $\sim 95$ \\
\hline Maximum & 179 & 262 \\
\hline Stand. Dev. (CV) & $21.0(18.3 \%)$ & $32.4(32.5 \%)$ \\
\hline 95\% C.I. & $76-160$ & $48-180$ \\
\hline \hline
\end{tabular}

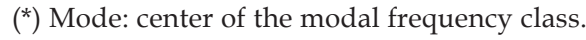




\section{O. flavescens}

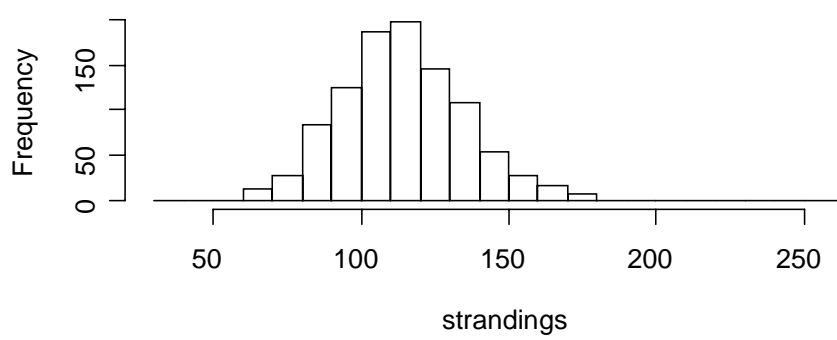

A. australis

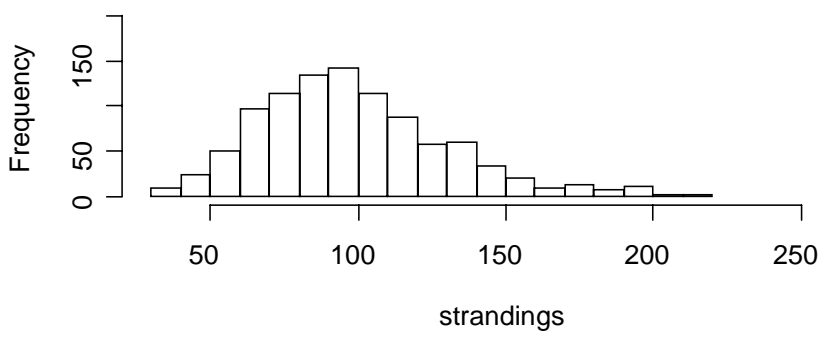

Figure 4. Distribution of 1000 Monte Carlo simulations of the numbers of annual strandings of sea lions and fur seals, south Brazil, based on model estimates from Model 2 with negative binomial distribution.

\section{Acknowledgements}

The data used in this research were collected by the Program for Conservation and Management of Pinnipeds (NEMA/IBAMA) with funds provided by Centro de Mamíferos Aquáticos - IBAMA, Fundo Nacional do Meio Ambiente, Fundação O Boticário de Proteção à Natureza, Superintendência do Porto do Rio Grande e Fundação Universidade Federal do Rio Grande. The cited Program was established in 1991 to promote integration among research groups, implement actions aimed at the conservation of pinnipeds in Rio Grande do Sul, and provide environmental education to communities involved.

The authors grateful acknowledge the many suggestions provided by Eduardo R. Secchi, Fernanda F. C. Marques and Nélio B. Barros which helped improve text and analysis.

\section{References}

Burnham, K. AND ANDerson, D. (2002) ModelSelection and MultiModel Inference ( $2^{\text {nd }}$ Edition). Springer Verlag. Berlin. 496p.

Dobson, A. J. (2002) An Introduction to Generalized Linear Models. Chapmann \& Hall. New York. 221p.

McCullagh, P. AND Nelder, J.A. (1989) Generalized Linear Models ( $2^{\text {nd }}$ Edition). Chapman \& Hall. New York. 511p.

Pinedo, M.C. (1990) Ocorrências de pinípedes na costa brasileira. Garcia de Orta, Serie Zoologia, Lisboa 15(2): 37-48.

Pinedo, M.C., Rosas, F.C. and Marmontel, M. (1992) Cetáceos e Pinípedes do Brasil: uma revisão dos registros e guia para identificação das espécies. UNEP/FUA, Manaus, Brasil. 213p.
R Development CoRe TeAm (2004) R: a language and environment for statistical computing. R Foundation for Statistical Computing. Viena. Available at: <http://www.R-project.org>.

Rosas, F.C. (1989) Aspectos da dinâmica populacional e interações com a pesca, do leão marinho do Sul, Otaria flavescens (Shaw, 1800) (Pinnipedia, Otaridae), no litoral sul do Rio Grande do Sul, Brasil. M.Sc. Dissertation in Biologcal Oceanography, FURG. Rio Grande. 88p.

Rosas, F.C.W., Pinedo, M.C., Marmontel, M. and Haimovici, M. (1994) Seasonal movements of the South American sea lion (Otaria flavescens, Shaw) on the Rio Grande do Sul coast, Brazil. Mammalia 58(1): 51-59.

SchwARTZ, G. (1978) Estimating the dimension of a model. Annals of Statistics 6(2): 461- 464.

Seeliger, U., Odebrecht, C. and Castelo, J.P. (Eds) (1997) Subtropical Convergente Environments: The coast and Sea in the Southwestern Atlantic. Springer Verlag. 308p.

SILvA, K.G. (2004) Os pinípedes no Brasil: ocorrências, estimativas populacionais e conservação. Ph.D. Thesis in Biological Oceanography, FURG. Rio Grande. 242p.

VAz-FerREIRA, R. (1981) South American sea lion Otaria flavescens (Shaw). Pages 39-65 in Rigway, S. and HarRISON, R. (Eds) Handbook of Marine Mammals, vol.2, Seals. Academic Press, New York.

Venables, W.N. And Ripley, B.D. (2002) Modern Applied Statistics with $S .4^{\text {th }}$ Ed. Springer Verlag.

Venables, W.N. and Dichmont, C.M. (2004) GLMs, GAMs and GLMMs: an overview of theory for applications in fisheries research. Fisheries Research 70: 319-337.

Received 26 April 2005. Accepted 2 June 2005. 